\title{
In Vitro Antifungal Activity of Equol against Candida albicans
}

\author{
Jeong Ah Lee and Hee Youn Chee* \\ Department of Cell Biology, College of Medicine, Konyang University, Daejeon 302-718, Korea
}

(Received June 1, 2010. Accepted August 17, 2010)

In this study, we demonstrate that equol has fungicidal activities against Candida albicans. The minimum inhibitory and minimum fungicidal concentrations of equol against $C$. albicans were 516 and $1,032 \mu \mathrm{M}$, respectively. Two separate viability assays found that equol changed the integrity of the $C$. albicans cell membrane, possibly by formation of membrane lesions. Scanning electron microscopy demonstrated ultrastructural changes.

KEWORDS : Candida albicans, Equol, Fungicidal activities

Candida albicans is a commensal yeast that is normally present as part of the microflora in the gastrointestinal tract (GIT) [1]. Overgrowth of C. albicans is typically controlled by commensal bacteria indigenous to the GIT [2]. However, if the balance of normal microflora is disrupted, such as upon administration of broad spectrum antibiotics or in an immunocompromised state [3, 4], overgrowth of candida can occur and candidasis can result.

Equol is an isoflavandiol and one of the main isoflavones found in soybeans, and it is metabolized from daidzein by intestinal bacteria. Its production in humans may depend on the presence of bacterial strains [5, 6]. Approximately $30 \sim 50 \%$ of the human population is capable of producing equol from daidzein in their GITs [7].

Recently, equol has received considerable attention due to its diverse biological activities that include antioxidant and antitumor properties [8-10]. However, little is known concerning its antimicrobial activities. The present study investigated the antifungal properties of equol against $C$. albicans.

Equol purchased from LC Laboratories (Boston, MA, USA) was dissolved in ethanol. C. albicans (KCTC 7965) obtained from the Korean Collection of Type Culture was maintained on Sabouraud dextrose agar (SDA) at $35^{\circ} \mathrm{C}$. The minimum inhibitory concentration (MIC) of equol was determined by microdilution broth assay performed according to National Committee for Clinical Laboratory Standards criteria (reference documents M-27) with some modifications [11]. A stock suspension of yeast cells was prepared by inoculating one colony obtained from an agar plate into Sabouraud dextrose broth, followed by incubation for $24 \mathrm{hr}$ at $35^{\circ} \mathrm{C}$. To prepare the inocula, yeast cell suspensions were adjusted to match the turbidity of a 0.5 McFarland standard (i.e., optical density $=0.12 \sim 0.15$ at $530 \mathrm{~nm}$, corresponding to $1 \sim 5 \times 10^{6}$ colony forming units

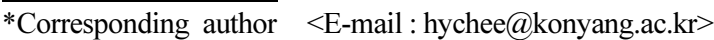

$(\mathrm{CFU}) / \mathrm{mL})$ in RPMI 1640. The suspension was diluted with RPMI 1640 to prepare a final inoculum suspension $\left(1 \times 10^{3} \mathrm{CFU} / \mathrm{mL}\right)$. A microdilution broth assay was performed in a 96-well, flat-bottomed microtiter plate. One hundred microliter aliquots of various concentrations of equol in RPMI 1640 were then added to each well, followed by an equal volume of yeast cell suspension. Each microtiter plate was incubated at $35^{\circ} \mathrm{C}$ for $24 \mathrm{hr}$. Control wells contained yeast cell suspension in RPMI 1640. Ketoconazole was used as a standard antifungal agent. MIC determinations were made by visual examination of growth inhibition [12]. The lowest concentration showing no visible growth was determined to be the MIC. MIC assay was performed at least three times. To determine fungistatic or fungicidal activity, wells showing no visible growth were subcultured onto SDA with $50 \mu \mathrm{L}$ of inoculum, followed by incubaiton at $28^{\circ} \mathrm{C}$ for 3 days to determine whether or not growth could resume. Lack of growth was interpreted to mean that the treatment had been fungicidal. Minimum fungicidal concentration (MFC) was determined from the wells showing no further growth. To confirm the fungicidal mode of equol, yeast cells were stained with FUN-1 viability stain (Molecular Probes, Eugene, OR, USA) as well as with a Live/Dead FungaLight yeast viability kit consisting of SYTO-9 and propidium iodide (Molecular Probes).

Ultrastructural changes in yeast cells following equol treatment were ascertained by scanning electron microscopy (SEM). Cells exposed to equol were incubated, harvested by centrifugation, and washed twice with phosphate buffed saline ( $\mathrm{pH}$ 7.2). The final cell pellet was fixed with $2.5 \%$ glutaraldehyde and placed on a coverslip treated with poly-L-lysine. The coverslip was washed in sodium cacodylate buffer and dehydrated in a graded ethanol series. The dehydrated coverslip was then critical-point dried, sputter-coated with gold, and assessed using a model S4800 scanning electron microscope (Hitachi, Tokyo, Japan) using 


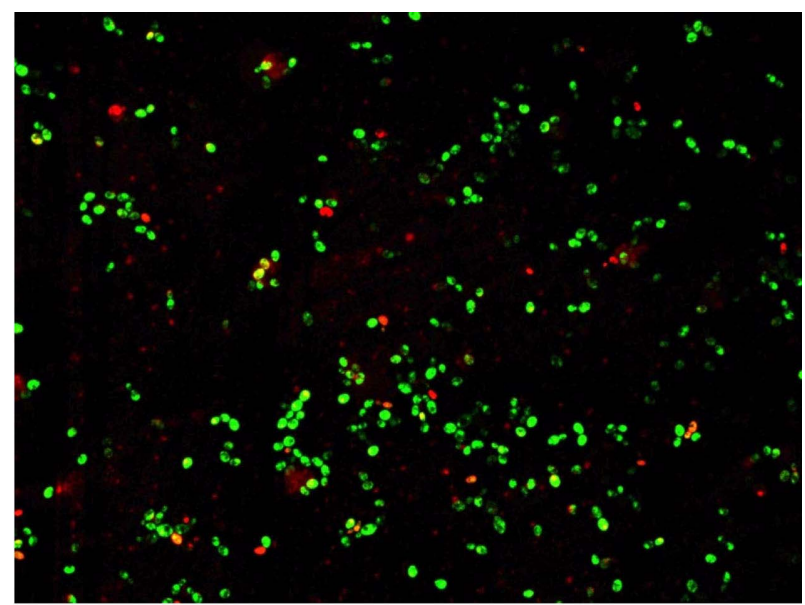

A

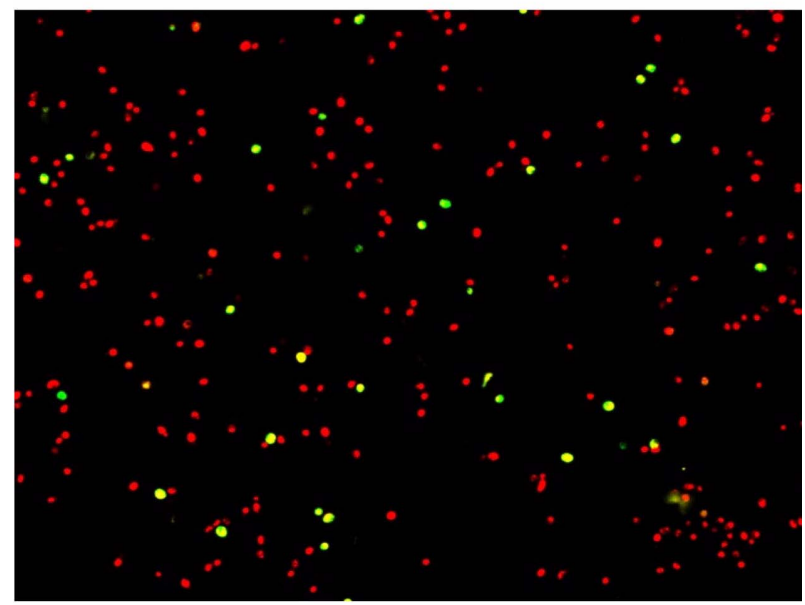

B

Fig. 1. Fluorescent micrographs of Candida albicans. A, Control cells showing green color indicate live cells; $\mathrm{B}$, Equol-treated cells at the minimum fungicidal concentration showing orange red color indicate dead cells $(\times 400)$.

standard operating conditions.

The results of the antifungal assay revealed that equol possessed potent antifungal activity against $C$. albicans. In the microdilution broth assay, the MIC of equol against $C$. albicans was $516 \mu \mathrm{M}$. The MFC of equol was subsequently determined to be $1,032 \mu \mathrm{M}$. The MIC of ketoconazole was $50 \mu \mathrm{g} / \mathrm{mL}$. Fluorescent microscopic observation was performed to investigate the effect of equol on the integrity of fungal cell membranes using propidium iodide as a fluorescent marker. Upon staining of fungal cells using a commercial viability kit, most equol-treated cells demonstrated an orange-red color at the MFC, which indicates altered cell membrane integrity, whereas most cells in the control well exhibited green fluorescence (Fig. 1).

The above results suggest that equol is capable of changing the integrity of the cell membrane, possibly by promoting the development of membrane lesions. Using FUN-1 viability staining, only metabolically active (i.e., liv-

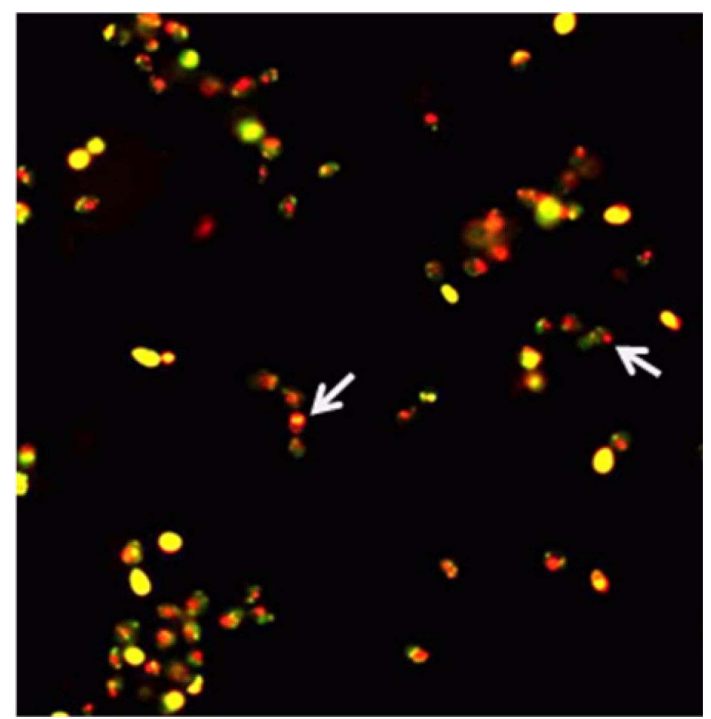

A



B

Fig. 2. Fluorescence microscopy of Candida albicans stained with Fun I viability kit. A, Cells in control: orange-red intracellular vacuolar structure (arrows); B, Cells treated with equol at the minimum fungicidal concentration; no orange-red intracellular vacuolar structure $(\times 400)$.

ing) cells in the control wells displayed an orange-red fluorescent cylindrical intravacuolar structure (CIVS), whereas equol-treated cells showed no intravacuolar structure (Fig. 2). Formation of CIVS requires both membrane integrity and metabolic capacity of viable yeast [13]. Therefore, the absence of CIVS in cells from the treated cells was indicative of cell death.

SEM of equol-treated $C$. albicans cells revealed ultrastructural changes, including cell surface abnormalities and burst cells (Fig. 3). These observations are indicative of an antifungal effect for equol.

Equol is produced in the GIT, of which C. albicans is a 


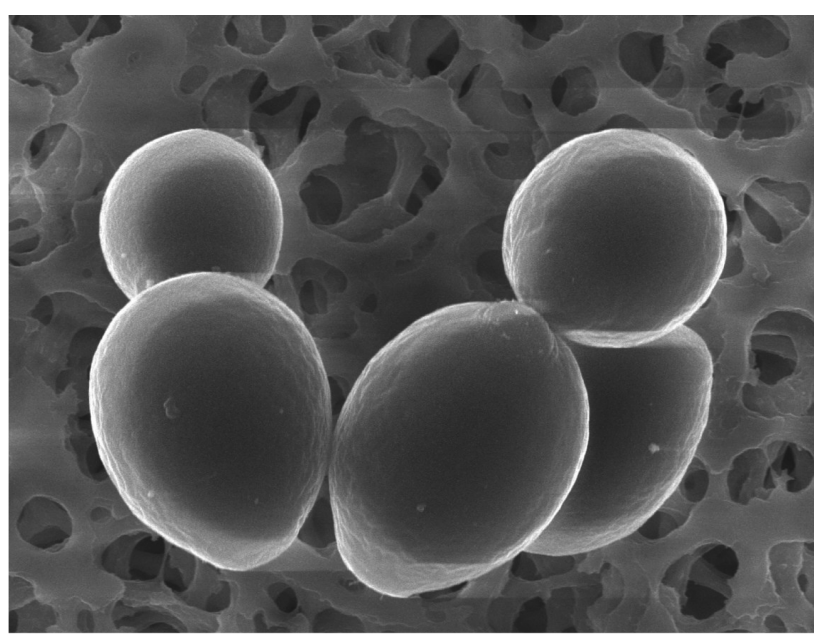

A

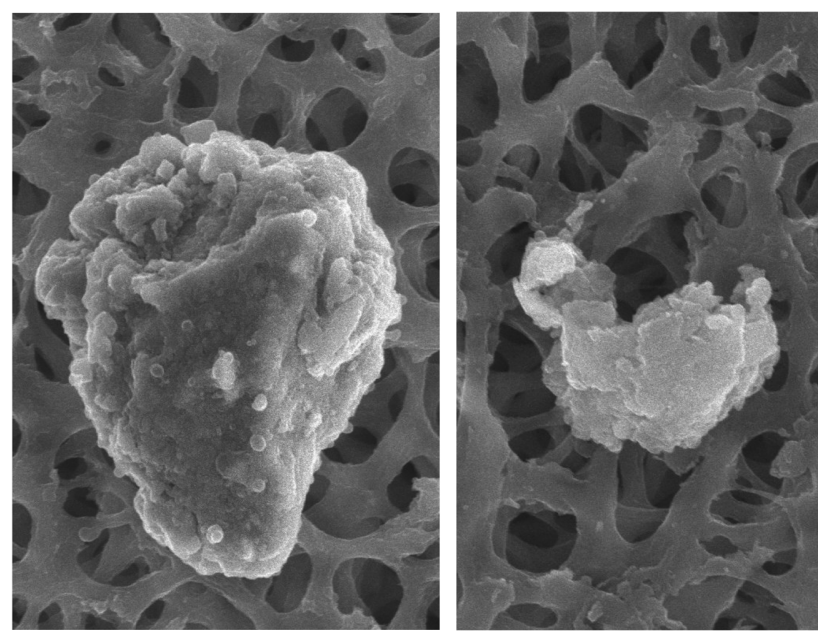

B

Fig. 3. Scanning electron microscopic images. A, Untreated Candida albicans; B, C. albicans treated with equol at minimum fungicidal concentration for $24 \mathrm{hr}(\times 10,000)$.

normal inhabitant. The present results indicate that equol can reduce $C$. albicans viability, which provides some insight into the possible effect of equol on the growth of C. albicans in the GIT. In addition, due to the development of drug resistance as well as side effects of certain antifungal agents, the search for novel antifungal agents has become that more urgent. Most available antifungal agents have fungistatic activities [14]. Thus, discovery of novel antifungal agents with fungicidal activity may be important in developing future treatments. The present results implicate equol as a potential antifungal agent. Details concerning the mechanism of the antifungal activity of equol on $C$. albicans growth in the GIT require more study.

\section{References}

1. Cohen R, Roth FJ, Delgado E, Ahearn DG, Kalser MH. Fungal flora of the normal human small and large intestine. $\mathrm{N}$ Engl J Med 1969;280:638-41.

2. Kennedy MJ, Volz PA. Ecology of Candida albicans gut colonization: inhibition of Candida adhesion, colonization, and dissemination from the gastrointestinal tract by bacterial antagonism. Infect Immun 1985;49:654-63.

3. Bodey GP. Candidiasis in cancer patients. Am J Med 1984; 77:13-9.

4. Kennedy MJ, Volz PA. Effect of various antibiotics on gastrointestinal colonization and dissemination by Candida albicans. Sabouraudia 1985;23:265-73.

5. Hur HG, Lay JO Jr, Beger RD, Freeman JP, Rafii F. Isolation of human intestinal bacteria metabolizing the natural isoflavone glycosides daidzin and genistin. Arch Microbiol 2000;174:422-8.

6. Atkinson C, Frankenfeld CL, Lampe JW. Gut bacterial metabolism of the soy isoflavone daidzein: exploring the relevance to human health. Exp Biol Med (Maywood) 2005;230:15570 .

7. Lampe JW, Karr SC, Hutchins AM, Slavin JL. Urinary equol excretion with a soy challenge: influence of habitual diet. Proc Soc Exp Biol Med 1998;21:335-9.

8. Wiseman H, O'Reilly JD, Adlercreutz H, Mallet AI, Bowey EA, Rowland IR, Sanders TA. Isoflavone phytoestrogens consumed in soy decrease $\mathrm{F}(2)$-isoprostane concentrations and increase resistance of low-density lipoprotein to oxidation in humans. Am J Clin Nutr 2000;72:395-400.

9. Hedlund TE, Johannes WU, Miller GJ. Soy isoflavonoid equol modulates the growth of benign and malignant prostatic epithelial cells in vitro. Prostate 2003;54:68-78.

10. Lund TD, Munson DJ, Haldy ME, Setchell KD, Lephart ED, Handa RJ. Equol is a novel anti-androgen that inhibits prostate growth and hormone feedback. Biol Reprod 2004;70: 1188-95.

11. National Committee for Clinical Laboratory Standards. Reference method for broth dilution antifungal susceptibility testing of yeasts: approved standard. Document M27-A. Wayne: PA: National Committee for Clinical Laboratory Standards; 1997.

12. Lozano-Chiu M, Arikan S, Paetznick VL, Anaissie EJ, Rex JH. Optimizing voriconazole susceptibility testing of Candida: effects of incubation time, endpoint rule, species of Candida, and level of fluconazole susceptibility. J Clin Microbiol 1999;37:2755-9.

13. Henry-Stanley MJ, Garni RM, Wells CL. Adaptation of FUN1 and Calcofluor white stains to assess the ability of viable and nonviable yeast to adhere to and be internalized by cultured mammalian cells. J Microbial Methods 2004;59:289-92.

14. Rapp RP. Changing strategies for the management of invasive fungal infections. Pharmacotherapy 2004;24(2 Pt 2):4S$28 \mathrm{~S}$. 